\title{
Interference of Selected Palmer Amaranth (Amaranthus palmeri) Biotypes in Soybean (Glycine max)
}

\author{
Aman Chandi, ${ }^{1}$ David L. Jordan, ${ }^{1}$ Alan C. York, ${ }^{1}$ Susana R. Milla-Lewis, ${ }^{1}$ \\ James D. Burton, ${ }^{2}$ A. Stanley Culpepper, ${ }^{3}$ and Jared R. Whitaker ${ }^{4}$ \\ ${ }^{1}$ Department of Crop Science, North Carolina State University, P.O. Box 7620, Raleigh, NC 27695-7620, USA \\ ${ }^{2}$ Department of Horticulture Science, North Carolina State University, P.O. Box 7609, Raleigh, NC 27695, USA \\ ${ }^{3}$ Department of Crop and Soil Sciences, University of Georgia, P.O. Box 478, Tifton, GA 31794, USA \\ ${ }^{4}$ Department of Crop and Soil Sciences, University of Georgia-Southeast District, P.O. Box 8112, Statesboro, GA 30460, USA
}

Correspondence should be addressed to David L. Jordan, david_jordan@ncsu.edu

Received 30 April 2012; Revised 16 July 2012; Accepted 20 July 2012

Academic Editor: Kassim Al-Khatib

Copyright () 2012 Aman Chandi et al. This is an open access article distributed under the Creative Commons Attribution License, which permits unrestricted use, distribution, and reproduction in any medium, provided the original work is properly cited.

Palmer amaranth (Amaranthus palmeri S. Wats.) has become difficult to control in row crops due to selection for biotypes that are no longer controlled by acetolactate synthase inhibiting herbicides and/or glyphosate. Early season interference in soybean [Glycine $\max (\mathrm{L}$.$) Merr.] for 40$ days after emergence by three glyphosate-resistant (GR) and three glyphosate-susceptible (GS) Palmer amaranth biotypes from Georgia and North Carolina was compared in the greenhouse. A field experiment over 2 years compared season-long interference of these biotypes in soybean. The six Palmer amaranth biotypes reduced soybean height similarly in the greenhouse but did not affect soybean height in the field. Reduction in soybean fresh weight and dry weight in the greenhouse; and soybean yield in the field varied by Palmer amaranth biotypes. Soybean yield was reduced $21 \%$ by Palmer amaranth at the established field density of 0.37 plant $\mathrm{m}^{-2}$. When Palmer amaranth biotypes were grouped by response to glyphosate, the GS group reduced fresh weight, dry weight, and yield of soybean more than the GR group. The results indicate a possible small competitive disadvantage associated with glyphosate resistance, but observed differences among biotypes might also be associated with characteristics within and among biotypes other than glyphosate resistance.

\section{Introduction}

Palmer amaranth is one of the most troublesome weeds of agronomic crops in the southeastern United States [1-3] because of its competitive ability, $\mathrm{C}_{4}$ photosynthesis, higher water use efficiency, and rapid growth rate $[4,5]$. This weed also possesses drought tolerance mechanisms which allow survival under limited water availability $[6-8]$ and it adapts readily to shading [9]. Several biotypes of Palmer amaranth have evolved resistance to herbicides representing different modes of action, including 5-enolpyruvylshikimate-3phosphate synthase (EPSPS) inhibitors, mitotic inhibitors, acetolactate synthase (ALS) inhibitors, and photosynthetic inhibitors [10], which make it challenging to control in cropping systems.

Species, density, and time of emergence with respect to the crop determine the relative competitiveness of pigweed species [11-14]. Interference of pigweed species including common waterhemp (Amaranthus rudis Sauer) [15-17], Palmer amaranth $[11,17,18]$, and redroot pigweed (Amaranthus retroflexus L.) $[14,17,19-22]$ has been evaluated in soybean. Soybean yield reduction as a result of interference increased from $17 \%$ to $68 \%$ with an increase in Palmer amaranth density from 0.33 to 10 plants $\mathrm{m}^{-1}$ of row length [11]. Furthermore, in the same study, correlation between soybean yield reduction and Palmer amaranth density was linear up to two Palmer amaranth plants $\mathrm{m}^{-1}$ of row, indicating that intraspecific interference between adjacent Palmer amaranth plants began at greater densities. Monks and Oliver [18] studied the competitive influence of common cocklebur (Xanthium strumarium L.), johnsongrass [Sorghum helpens (L.) Pers.], Palmer amaranth, sicklepod [Cassia obtusifolia (L.) H. S. Irwin and Barneby], and tall morningglory [Ipomea purpurea (L.) Roth] on biomass and yield of two soybean 
cultivars in Arkansas. Their results indicated a reduction in biomass of both soybean cultivars when growing within $50 \mathrm{~cm}$ of Palmer amaranth and reduction in soybean seed yield within a distance of $25 \mathrm{~cm}$ of Palmer amaranth. The distance of influence of Palmer amaranth was among the greatest for the weeds evaluated in this study. Among the three pigweed species (Palmer amaranth, redroot pigweed, and common waterhemp) interfering with soybean, Palmer amaranth accumulated the greatest biomass, followed by common waterhemp and then redroot pigweed [17]. Further, Palmer amaranth planted along with soybean at a density of 8 plants $\mathrm{m}^{-1}$ of row resulted in the greatest $(79 \%)$ reduction in soybean yield, followed by common waterhemp (56\%) and then redroot pigweed (38\%).

Interference of Palmer amaranth has also been studied in other crops [23-29]. Palmer amaranth growing at a density of 0.9 plants $\mathrm{m}^{-2}$ resulted in up to $92 \%$ reduction in cotton (Gossypium hirsutum L.) lint yield [23]. While a linear decrease in cotton yield was observed from 13\% to $54 \%$ with an increase in Palmer amaranth density from 1 to 10 plants $/ \mathrm{m}^{2}$, volume and biomass of Palmer amaranth remained unaffected by intraspecific competition at all densities [24]. Palmer amaranth reduced corn leaf area index (LAI) and corn grain yield from $11 \%$ to $91 \%$ as density increased from 0.5 to 8 plants $/ \mathrm{m}^{2}[25,26]$. There was a negative linear relationship between grain sorghum [Sorghum bicolor (L.) Moench] yield and density of Palmer amaranth. Increasing weed density decreased grain sorghum yield by reducing the numbers of grains produced in panicles [27]. Season-long Palmer amaranth interference in peanut (Arachis hypogaea L.) reduced peanut canopy diameter and one plant $\mathrm{m}^{-1}$ of row resulted in a predicted yield loss of up to $28 \%$ [28]. Yield reductions from 30 to $94 \%$ were reported in sweet potato [Ipomoea batatas (L.) Lam.] by Palmer amaranth densities ranging from 0.5 to 6.5 plants $\mathrm{m}^{-1}$ row [29].

Many biotypes of Palmer amaranth have developed confirmed resistance to glyphosate in the southern United States, making it difficult to manage [30-33]. Herbicide-resistant weed biotypes sometimes have a fitness penalty compared with nonresistant wild types [34-45]. Several components of fitness of maternally inherited triazine-resistant smooth pigweed (Amaranthus hybridus L.) were reduced, including early seedling emergence, early growth, mid-season leaf number, and total above-ground biomass, but differences varied among years and populations $[36,37]$. Evolved resistance in Powell's amaranth (Amaranthus powellii S. Wats.) to ALSinhibiting herbicides resulted in thinner roots and stems and reduced leaf area, resulting in a $67 \%$ reduction in aboveground vegetative mass and a $30 \%$ reduction in seed biomass [38]. A mutant of blackgrass (Alopecurus myosuroides Huds.) resistant to herbicides that inhibit acetyl coenzyme A carboxylase (ACCase) when grown in competition with wheat (Triticum aestivum L.) under limited water supply had a $6 \%, 42 \%$, and $26 \%$ reduction in height, vegetative, and reproductive biomass, respectively, as compared to the wild biotype [39]. The proportion of resistant individuals in segregating $\mathrm{F}_{2}$ populations of rigid ryegrass (Lolium rigidum Gaud.) decreased as compared to susceptible individuals over a period of 4 years [40, 41]. Baucom and Mauricio [42] reported a high fitness cost of glyphosate resistance in tall morningglory. Glyphosate-resistant genotypes produced fewer seeds as compared to susceptible genotypes in the absence of selection pressure from glyphosate.

Determining relative differences in interference of GR and GS Palmer amaranth biotypes in soybean could be of benefit to evaluate possible competitive disadvantage associated with GR trait. Therefore, greenhouse experiment was conducted to compare early season interference by selected GR and GS biotypes of Palmer amaranth grown with soybean. A field experiment was conducted to study the effect of season-long interference by these biotypes on soybean.

\section{Materials and Methods}

2.1. Greenhouse Experiment. Seeds from six Palmer amaranth biotypes [31] collected from fields in Georgia and North Carolina during the fall of 2005 were grown along with Roundup Ready soybean cultivar AG6301 (Monsanto Company, St. Louis, MO 63167, USA) in $15 \mathrm{~cm}$ round plastic pots containing commercial potting soil (Fafard 4P potting mix, Conrad Fafard Inc. Agawam, MA 01001). Three Palmer amaranth biotypes were GR (one from North Carolina and two from Georgia) and three were GS (one from North Carolina and two from Georgia) (Figure 1). Approximately six soybean seeds and 25 Palmer amaranth seeds were planted in two parallel rows spaced $2.5 \mathrm{~cm}$ apart in each pot. Seedlings were thinned to one soybean and one Palmer amaranth plant pot $^{-1} 10$ days after emergence (DAE). Controls included a single soybean or Palmer amaranth plant pot $^{-1}$. Plants were fertilized (Scotts Starter Fertilizer, The Scotts Company LLC, Marysville, OH 43041, USA) with $25 \mathrm{~mL}$ of a $4.6 \mathrm{~g} \mathrm{~L}^{-1}$ fertilizer solution per pot every 10 days to ensure optimum plant growth. Pots were spaced sufficiently enough to avoid shading from adjacent pots during the entire duration of experiment. Plants were irrigated daily using an overhead sprinkler system. The greenhouse was maintained at $35 \pm 5^{\circ} \mathrm{C}$, and natural illumination was supplemented for 14 hours each day with metal halide lighting $\left(400 \mu \mathrm{mol} \mathrm{m}^{-2} \mathrm{~s}^{-1}\right)$ (Hubbell Lighting, Inc., Greenville, SC 29607). The experimental design was a randomized complete block with treatments replicated 10 times and the experiment was repeated.

Height of the Palmer amaranth and soybean was determined every 5 days beginning 1 week after pots were thinned, corresponding to $15,20,25,30,35$, and 40 DAE. Plant height was measured from the soil surface to the base of the upper most fully expanded leaf for both soybean and Palmer amaranth plants. At 40 DAE, Palmer amaranth and soybean plants were severed at the soil surface to determine shoot fresh weight and dry weight. The samples were dried in paper bags in oven at $60^{\circ} \mathrm{C}$ for 72 hours for dry weight measurements.

Data for percent reduction in plant height and percent reduction in fresh and dry weight relative to controls without interference were subjected to ANOVA using Proc. GLM (Statistical Analysis Systems, version 9.1, SAS Institute Inc., 

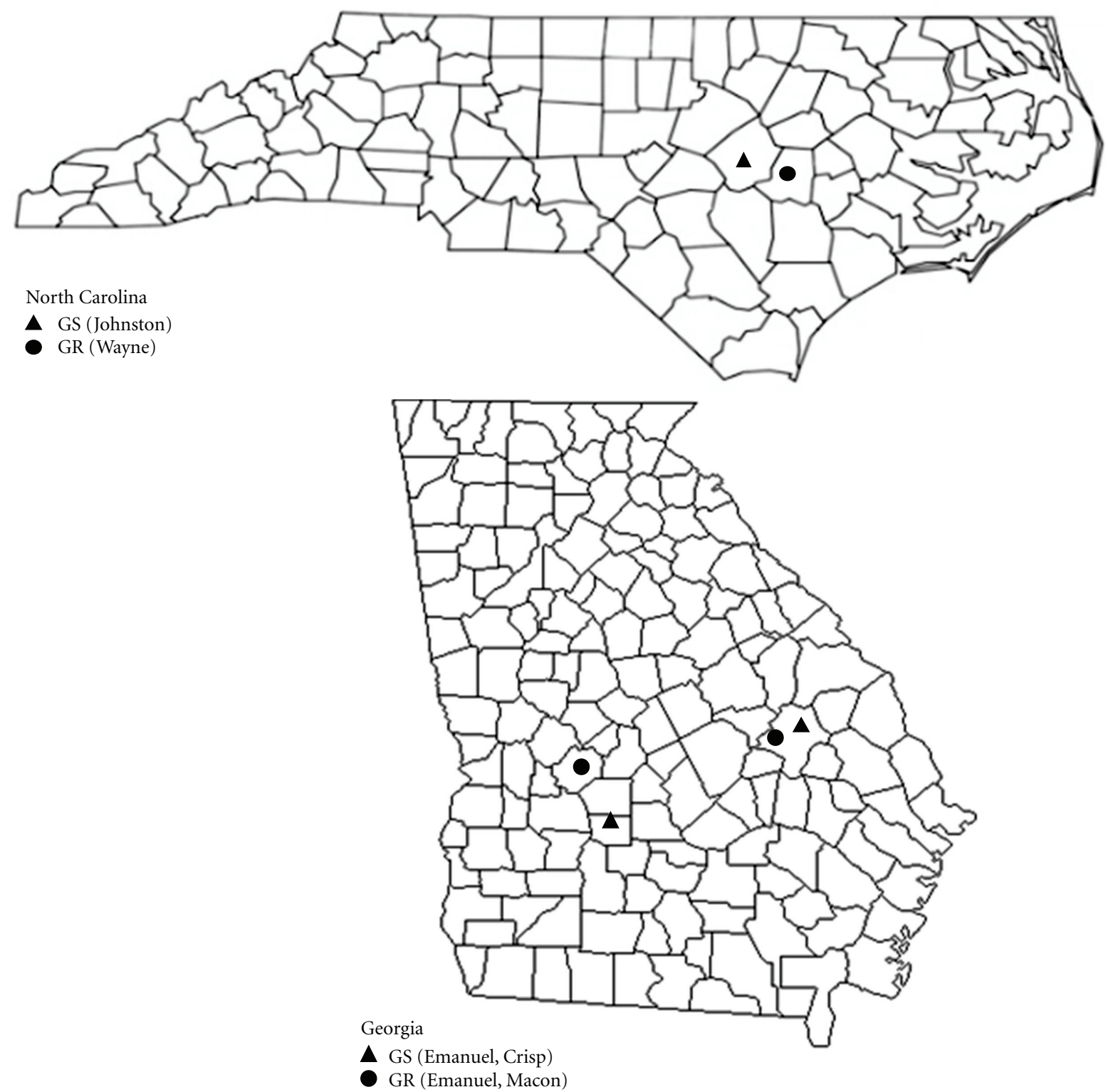

FIgURE 1: Locations of North Carolina and Georgia biotypes used in the study.

SAS Campus Drive, Cary, NC 2751, USA). Due to lack of interaction data were pooled over the two runs. In a separate analysis, data were grouped for biotypes expressing resistance or susceptibility to glyphosate (GR biotype group and GS biotype group) and subjected to ANOVA. Means of significant effects were separated using Fisher's Protected LSD test.

2.2. Field Experiment. The experiment was conducted in conventionally planted (row to row distance $=91 \mathrm{~cm}$ ) Roundup Ready soybean cultivar AG6301 during 2008 and 2009 at the Cunningham Research Station near Kinston, NC on a Norfolk loamy sand (fine-loamy, kaolinitic, thermic Typic Kandiudults). Plot size was one row by $6 \mathrm{~m}$, and two border rows were included between experimental units. Approximately 10 seeds of each Palmer amaranth biotype were planted $3 \mathrm{~cm}$ apart and $4 \mathrm{~cm}$ to the side of soybean row immediately after planting soybean in the middle of the plot. Both GR and GS biotypes were thinned to one plant per plot (one per row) about 20 DAE. At 35 DAE, Palmer amaranth plants were covered with large plastic bags and potassium salt of glyphosate (Roundup Weathermax, Monsanto Company, St. Louis, MO 63167, USA) at $1.1 \mathrm{~kg}$ ae ha $^{-1}$ was applied over the entire test area to control other weeds. For the reminder of the season, weeds other than the one desired Palmer amaranth per plot were removed by hand. A control was included without Palmer amaranth. The experimental design was a randomized complete block with eight replications.

Soybean height was recorded 30,60, 90, and $120 \mathrm{DAE}$ at a distance of $30,60,90$, and $120 \mathrm{~cm}$ on either side of Palmer amaranth within the soybean row. Mature soybean plants were harvested manually in row sections of 0 to 30 , 
31 to 60,61 to 90,91 to 120 , and 121 to $150 \mathrm{~cm}$ on either side of Palmer amaranth. Soybean plants were threshed using stationary thresher. Observations on soybean were converted to percent reduction in height and yield relative to the control in absence of Palmer amaranth.

Data for percent reduction in soybean height and yield were subjected to ANOVA as explained earlier when considering Palmer amaranth biotypes individually. In a separate analysis, data were grouped for biotypes expressing resistance or susceptibility to glyphosate (GR and GS biotype groups) and subjected to ANOVA. Means of significant main effects and interactions were separated using Fisher's Protected LSD test. Due to lack of interaction data were pooled over the two runs. Percent reduction in soybean yield was linearly regressed against distance from Palmer amaranth using Sigmaplot 12.0 (Systat Software Inc. 1735 Technology Drive, Suite 430, San Jose, CA 95110, USA). The regression expression used was $y=a x+b$, where, $y=$ percent reduction in yield, $x=$ distance from Palmer amaranth plant, and $a$ and $b$ are constants.

\section{Results and Discussion}

3.1. Greenhouse Experiment. Differences among individual Palmer amaranth biotypes were not observed for soybean height reduction at any of the six times that height was recorded (data not shown). Averaged over biotypes, soybean height was reduced $10,10,8,11,10$, and $5 \%$ at $15,20,25$, 30, 35, and $40 \mathrm{DAE}$ (data not shown). Differences among individual Palmer amaranth biotypes were observed for soybean fresh weight $(P \leq 0.05)$ and dry weight $(P \leq 0.10)$ reduction. Both fresh weight and dry weight reduction was similar with the Emanuel (GR), Macon, (GR), Crisp (GS), Emanuel (GS), and Johnston (GS) biotypes (Table 1). The Wayne (GR) biotype reduced fresh and dry weight less than the Macon (GR), Crisp (GS), and Emanuel (GS) biotypes.

When Palmer amaranth biotypes were grouped with respect to response to glyphosate, no differences in soybean height reduction were noted between the two groups (data not shown). However, differences among Palmer amaranth biotype groups were observed for soybean fresh weight $(P \leq$ $0.05)$ and dry weight $(P \leq 0.10)$ reduction. The GS biotype group reduced fresh weight and dry weight of soybean more than the GR biotype group (Table 1). Soybean fresh weight was reduced $31 \%$ and $23 \%$ as result of interference from the GS and GR Palmer amaranth biotype groups, respectively. Interference from GS and GR biotype groups reduced soybean dry weight by $27 \%$ and $21 \%$, respectively.

3.2. Field Experiment. Interference of Palmer amaranth biotypes and biotype groups did not affect soybean height at 30, 60,90 , or 120 DAE and at distance of $30,60,90$, or $120 \mathrm{~cm}$ from Palmer amaranth (data not shown). These results were unexpected given the competitive ability of Palmer amaranth [1-9, 11, 17, 18]. Chivinge and Schweppenhauser [46] reported that competition with smooth pigweed reduced branching, shoot dry weight, leaf area index, number of pods per plant, and grain yield of soybean, but plant height,
TABLE 1: Percent reduction in soybean fresh weight and dry weight at harvest (40 days after emergence) caused by early season interference by Palmer amaranth in greenhouse experiment. ${ }^{\mathrm{a}, \mathrm{b}}$

\begin{tabular}{lcc}
\hline Palmer amaranth biotype & $\begin{array}{c}\text { Fresh weight } \\
\text { reduction }\end{array}$ & $\begin{array}{c}\text { Dry weight } \\
\text { reduction }\end{array}$ \\
\hline \multicolumn{2}{c}{$\%$}
\end{tabular}

Individual Palmer amaranth biotypes ${ }^{\mathrm{c}}$

$\begin{array}{lcc}\text { Emanuel (GR) } & 24 \mathrm{ab} & 23 \mathrm{ab} \\ \text { Macon (GR) } & 31 \mathrm{a} & 28 \mathrm{a} \\ \text { Wayne (GR) } & 13 \mathrm{~b} & 11 \mathrm{~b} \\ \text { Crisp (GS) } & 31 \mathrm{a} & 26 \mathrm{a} \\ \text { Emanuel (GS) } & 37 \mathrm{a} & 31 \mathrm{a} \\ \text { Johnston (GS) } & 26 \mathrm{ab} & 24 \mathrm{ab}\end{array}$

Palmer amaranth biotypes grouped by response to glyphosate ${ }^{\mathrm{d}}$

\begin{tabular}{lll} 
GR group & $23 z$ & $21 z$ \\
GS group & $31 y$ & $27 y$ \\
\hline
\end{tabular}

${ }^{a}$ Data are pooled over runs of the experiment. Abbreviations: GR, glyphosate resistant; GS, glyphosate susceptible.

${ }^{\mathrm{b}}$ Means within a parameter and analysis followed by the same letter are not significantly different according to Fisher's Protected LSD test at $P \leq 0.05$ for fresh weight reduction and $P \leq 0.10$ for dry weight reduction.

${ }^{c}$ Consists of six Palmer amaranth biotypes.

${ }^{\mathrm{d}}$ Consists of a group of three glyphosate-resistant (GR) and a group of three glyphosate-susceptible (GS) Palmer amaranth biotypes.

number of seeds per pod, and 1000-seed weight were not affected. The main effects of year, biotype, distance, and their interactions were not significant for percent reduction in soybean height when Palmer amaranth biotypes were considered individually or as biotype groups at 30,60, 90, and $120 \mathrm{DAE}$ and at distance of $30,60,90$, and $120 \mathrm{~cm}$ from Palmer amaranth (data not shown). When Palmer amaranth biotypes were considered individually, the main effects of year, biotype, and distance from Palmer amaranth were significant for percent reduction in soybean yield (Table 2). However, the interactions of these factors were not significant. Similar results were obtained when Palmer amaranth biotypes were grouped based on response to glyphosate (GR and GS biotype groups).

There were differences in soybean yield reduction as a result of interference from individual Palmer amaranth biotypes averaged over years and five $30 \mathrm{~cm}$ distance increments from Palmer amaranth (Table 3). Interference from all GS biotypes reduced soybean yield similarly. Among GR biotypes, interference from the Emanuel biotype reduced soybean yield more than Macon and Wayne biotypes. Soybean yield reduction by the GR Emanuel biotype was similar to GS biotypes. When biotype groups were compared, interference from the GS biotype group reduced soybean yield more than the GR biotype group. The GS biotype group reduced soybean yield 23\% compared with 19\% reduction by the GR biotype group.

A significant effect of distance from Palmer amaranth was reflected in increasing yield of soybean as distance from Palmer amaranth increased (Figure 2). The greatest yield reduction, $34 \%$, was noted at $15 \mathrm{~cm}$ from Palmer amaranth 
TABle 2: $P>F$ for percent reduction in soybean yield caused by season-long interference by Palmer amaranth in field experiment. ${ }^{\text {a }}$

\begin{tabular}{|c|c|c|}
\hline Source of variation & $\begin{array}{c}\text { Individual Palmer } \\
\text { amaranth } \\
\text { biotypes }^{\mathrm{b}}\end{array}$ & $\begin{array}{c}\text { Palmer amaranth } \\
\text { biotypes grouped } \\
\text { by response to } \\
\text { glyphosate }^{\mathrm{c}}\end{array}$ \\
\hline & \multicolumn{2}{|c|}{$P>F$ value } \\
\hline Year & $<0.0001$ & $<0.0001$ \\
\hline Biotype & 0.0013 & 0.0010 \\
\hline Year $\times$ biotype & 0.9135 & 0.4459 \\
\hline Distance & $<0.0001$ & $<0.0001$ \\
\hline Year $\times$ distance & 0.1296 & 0.1457 \\
\hline Biotype $\times$ distance & 0.1980 & 0.8564 \\
\hline Year $\times$ biotype $\times$ distance & 0.9150 & 0.6201 \\
\hline Coefficient of variation (\%) & 90.4 & 96.3 \\
\hline
\end{tabular}

${ }^{\mathrm{a}}$ Data are pooled over runs of the experiment.

${ }^{\mathrm{b}}$ Consists of six Palmer amaranth biotypes.

${ }^{\mathrm{c} C o n s i s t s ~ o f ~ a ~ g r o u p ~ o f ~ t h r e e ~ g l y p h o s a t e-r e s i s t a n t ~(G R) ~ a n d ~ a ~ g r o u p ~ o f ~ t h r e e ~}$ glyphosate-susceptible (GS) Palmer amaranth biotypes.

TABle 3: Percent reduction in soybean yield caused by season-long interference by Palmer amaranth in field experiment. ${ }^{\mathrm{a}, \mathrm{b}}$

\begin{tabular}{lc}
\hline Palmer amaranth biotype & Yield reduction \\
\hline & $\%$ \\
Individual Palmer amaranth biotypes $^{\mathrm{c}}$ & \\
Emanuel (GR) & $24 \mathrm{a}$ \\
Macon (GR) & $17 \mathrm{~b}$ \\
Wayne (GR) & $16 \mathrm{~b}$ \\
Crisp (GS) & $24 \mathrm{a}$ \\
Emanuel (GS) & $22 \mathrm{a}$ \\
Johnston (GS) & $24 \mathrm{a}$ \\
Palmer amaranth biotypes grouped by response & \\
to glyphosate & \\
GR & $19 \mathrm{z}$ \\
GS & $23 \mathrm{y}$ \\
\hline
\end{tabular}

a Data are pooled over five $30 \mathrm{~cm}$ distance increments from Palmer amaranth and runs (years) of the experiment. Abbreviations: GR, glyphosate resistant; GS, glyphosate susceptible.

${ }^{\mathrm{b}}$ Means within a parameter and analysis followed by the same letter are not significantly different according to Fisher's Protected LSD test at $P \leq 0.05$.

${ }^{\mathrm{c}}$ Consists of six Palmer amaranth biotypes.

${ }^{\mathrm{d}}$ Consists of a group of three glyphosate-resistant and a group of three glyphosate-susceptible Palmer amaranth biotypes.

while yield was reduced $28 \%, 22 \%, 16 \%$, and $11 \%$ at $45 \mathrm{~cm}$, $75 \mathrm{~cm}, 105 \mathrm{~cm}$, and $135 \mathrm{~cm}$ from Palmer amaranth, respectively. Soybean yield and biomass reduction when growing within a distance of $25 \mathrm{~cm}$ and $50 \mathrm{~cm}$ of Palmer amaranth, respectively, were reported by Monks and Oliver [18].

Palmer amaranth density established in this experiment was 0.37 Palmer amaranth plants $\mathrm{m}^{-2}$ or 0.33 Palmer amaranth plants $\mathrm{m}^{-1}$ of row length (calculated based on effective harvested plot size of $3 \mathrm{~m}$ by $0.91 \mathrm{~m}$ ). Soybean yield loss corresponding to this density was $22 \%$ (averaged over five $30 \mathrm{~cm}$ distance increments from Palmer amaranth). Soybean

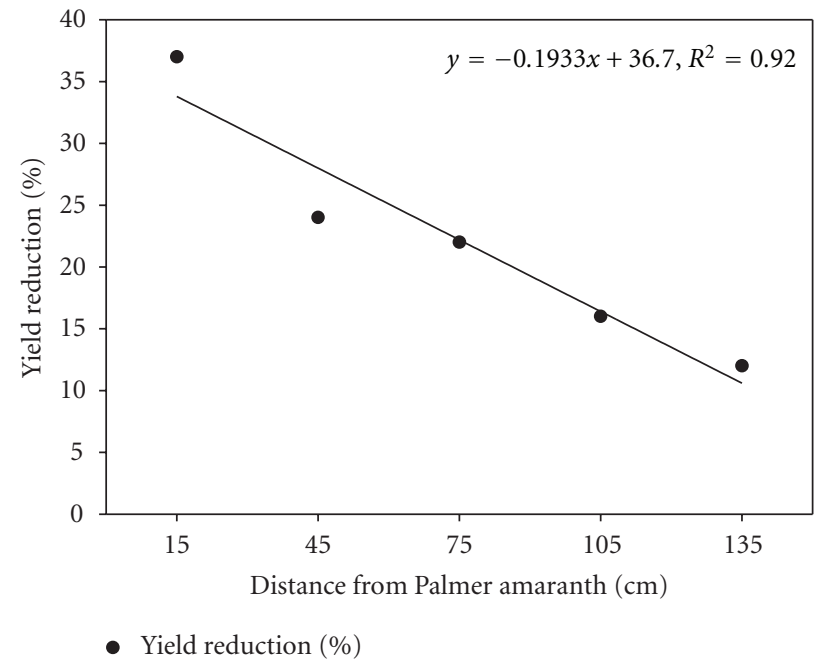

Figure 2: Percent reduction in soybean yield as influenced by distance from Palmer amaranth in the field experiment.

yield loss of $17 \%$ at a Palmer amaranth density of $0.33 \mathrm{~m}^{-1}$ of row was reported by Klingaman and Oliver [11]. Herbicide Application Decision Support System for field crops (WebHADSS version 2004.0.3) predicted soybean yield loss of $11.2 \%$ at density of 0.37 Palmer amaranth plants $\mathrm{m}^{-2}$.

Results from both the greenhouse and field studies indicate a possible small competitive disadvantage associated with the glyphosate resistance trait in the biotypes of Palmer amaranth examined. A fitness penalty associated with glyphosate resistance [40-42, 45] as well as other herbicides [36-39] has been reported previously. A fitness penalty associated with GR Palmer amaranth has not been reported. On the other hand, the observed differences may be due to reasons unrelated to glyphosate resistance. A wide range of phenotypic variation has been reported in Palmer amaranth accessions [47-50]. Genetic variability in Palmer amaranth biotypes used in this study was assessed in another experiment using Amplified Fragment Length Polymorphisms [51]. Pair-wise genetic similarity values were found to be relatively low, averaging 0.34 . The variation among GR and GS biotype groups used in this study was also found to be less than the overall genetic variability present within all the individual biotypes. It is possible that a high degree of phenotypic and genetic variability present among and within Palmer amaranth biotypes used in the study was responsible for the observed differences in interference.

\section{Conclusions}

Collectively, results from these experiments indicate that interference in soybean can vary among Palmer amaranth biotypes. Although data suggest that there may be a small competitive disadvantage due to the GR trait, a larger pool of biotypes is needed to conclusively define a fitness cost to glyphosate resistance in Palmer amaranth. The observed differences in interference may have been associated with 
inherent diversity existing within and among Palmer amaranth biotypes.

\section{Acknowledgments}

Syngenta Crop Protection and Monsanto Company provided partial funding for this research. Appreciation is expressed to Rick Seagroves, Jamie Hinton, Peter Eure, and Gurinderbir Chahal for technical assistance and to Navinderpal Singh and Chuck Foresman for providing advice on this project.

\section{References}

[1] T. M. Webster, "Weed survey-southern states," Proceedings Southern Weed Science Society, vol. 57, pp. 404-426, 2004.

[2] T. M. Webster, "Weed survey-southern states," Proceedings Southern Weed Science Society, vol. 58, pp. 291-306, 2005.

[3] T. M. Webster and H. D. Coble, "Changes in the weed species composition of the southern United States: 1974 to 1995," Weed Technology, vol. 11, no. 2, pp. 308-317, 1997.

[4] C. C. Black, T. M. Chen, and R. H. Brown, "Biochemical basis for plant competition," Weed Science, vol. 17, no. 3, pp. 338344, 1969.

[5] M. J. Horak and T. M. Loughin, "Growth analysis of four Amaranthus species," Weed Science, vol. 48, no. 3, pp. 347-355, 2000.

[6] J. Ehleringer, "Ecophysiology of Amaranthus palmeri, a sonoran desert summer annual," Oecologia, vol. 57, no. 1-2, pp. 107-112, 1983.

[7] G. Place, D. Bowman, M. Burton, and T. Rufty, "Root penetration through a high bulk density soil layer: differential response of a crop and weed species," Plant and Soil, vol. 307, no. 1-2, pp. 179-190, 2008.

[8] S. R. Wright, M. W. Jennette, H. D. Coble, and T. W. Rufty, "Root morphology of young Glycine max, Senna obtusifolia, and Amaranthus palmeri," Weed Science, vol. 47, no. 6, pp. 706-711, 1999.

[9] P. Jha, J. K. Norsworthy, M. B. Riley, D. G. Bielenberg, and W. Bridges Jr., "Acclimation of palmer amaranth (Amaranthus palmeri) to shading," Weed Science, vol. 56, no. 5, pp. 729-734, 2008.

[10] I. Heap, “The International Survey of Herbicide Resistant Weeds," 2012, http://www.weedscience.org.

[11] T. E. Klingaman and L. R. Oliver, "Palmer amaranth (Amaranthus palmeri) interference in soybeans (Glycine max)," Weed Science, vol. 42, no. 4, pp. 523-527, 1994.

[12] R. J. Aldrich, "Predicting crop yield reductions from weeds," Weed Technology, vol. 1, no. 3, pp. 199-206, 1987.

[13] S. Z. Knezevic, M. J. Horak, and R. L. Vanderlip, "Relative time of redroot pigweed (Amaranthus retroflexus L.) emergence is critical in pigweed-sorghum [Sorghum bicolor (L.) Moench] competition," Weed Science, vol. 45, no. 4, pp. 502-508, 1997.

[14] P. Cowan, S. E. Weaver, and C. J. Swanton, "Interference between pigweed (Amaranthus spp.), barnyardgrass (Echinochloa crus-galli), and soybean (Glycine max)," Weed Science, vol. 46, no. 5, pp. 533-539, 1998.

[15] R. G. Hartzler, B. A. Battles, and D. Nordby, "Effect of common waterhemp (Amaranthus rudis) emergence date on growth and fecundity in soybean," Weed Science, vol. 52, no. 2, pp. 242-245, 2004.
[16] S. M. Jones, R. J. Smeda, G. S. Smith, and W. G. Johnson, “The effect of waterhemp competition on soybean yield," Proceedings of North Central Weed Science Society, vol. 53, article 146, 1998.

[17] C. N. Bensch, M. J. Horak, and D. Peterson, "Interference of redroot pigweed (Amaranthus retroflexus), Palmer amaranth (A. palmeri), and common waterhemp (A. rudis) in soybean," Weed Science, vol. 51, no. 1, pp. 37-43, 2003.

[18] D. W. Monks and L. R. Oliver, "Interactions between soybean (Glycine max) cultivars and selected weeds," Weed Science, vol. 36, no. 6, pp. 770-774, 1988.

[19] A. Dieleman, A. S. Hamill, S. F. Weise, and C. J. Swanton, "Empirical models of pigweed (Amaranthus spp.) interference in soybean (Glycine max)," Weed Science, vol. 43, no. 4, pp. 612-618, 1995.

[20] A. Légère and M. M. Schreiber, "Competition and canopy architecture as affected by soybean (Glycine max) row width and density of redroot pigweed (Amaranthus retroflexus)," Weed Science, vol. 37, no. 1, pp. 84-92, 1989.

[21] P. L. Orwick and M. M. Schreiber, "Interference of redroot pigweed (Amaranthus retroflexus) and robust foxtail (Setaria viridis var. robusta-alba or var. robusta-purpurea) in soybeans (Glycine max)," Weed Science, vol. 27, no. 6, pp. 665-674, 1979.

[22] J. L. Shurtleff and H. D. Coble, "Interference of certain broadleaf weed species in soybean (Glycine max)," Weed Science, vol. 33, pp. 654-657, 1985.

[23] M. W. Rowland, D. S. Murray, and L. M. Verhalen, "Fullseason Palmer amaranth (Amaranthus palmeri) interference with cotton (Gossypium hirsutum)," Weed Science, vol. 47, no. 3, pp. 305-309, 1999.

[24] G. D. Morgan, P. A. Baumann, and J. M. Chandler, "Competitive impact of Palmer amaranth (Amaranthus palmeri) on cotton (Gossypium hirsutum) development and yield," Weed Technology, vol. 15, no. 3, pp. 108-112, 2001.

[25] R. A. Massinga and R. S. Curie, "Impact of Palmer amaranth (Amaranthus palmeri) on corn (Zea mays) grain yield and quality of forage," Weed Technology, vol. 16, no. 3, pp. 532536, 2002.

[26] R. A. Massinga, R. S. Currie, M. J. Horak, and J. Boyer, "Interference of Palmer amaranth in corn," Weed Science, vol. 49, no. 2, pp. 202-208, 2001.

[27] J. W. Moore, D. S. Murray, and R. B. Westerman, "Palmer amaranth (Amaranthus palmeri) effects on the harvest and yield of grain sorghum (Sorghum bicolor)," Weed Technology, vol. 18 , no. 1, pp. 23-29, 2004.

[28] I. C. Burke, M. Schroeder, W. E. Thomas, and J. W. Wilcut, "Palmer amaranth interference and seed production in peanut," Weed Technology, vol. 21, no. 2, pp. 367-371, 2007.

[29] S. L. Meyers, K. M. Jennings, J. R. Schultheis, and D. W. Monks, "Interference of palmer amaranth (Amaranthus palmeri) in sweetpotato," Weed Science, vol. 58, no. 3, pp. 199203, 2010.

[30] A. S. Culpepper, T. L. Grey, W. K. Vencill et al., "Glyphosateresistant Palmer amaranth (Amaranthus palmeri) confirmed in Georgia," Weed Science, vol. 54, no. 4, pp. 620-626, 2006.

[31] A. S. Culpepper, J. R. Whitaker, A. W. MacRae, and A. C. York, "Weed science: distribution of glyphosate-resistant palmer amaranth (Amaranthus palmeri) in Georgia and North Carolina during 2005 and 2006," Journal of Cotton Science, vol. 12, no. 3, pp. 306-310, 2008.

[32] J. K. Norsworthy, G. M. Griffith, R. C. Scott, K. L. Smith, and L. R. Oliver, "Confirmation and control of glyphosate-resistant Palmer amaranth (Amaranthus palmeri) in Arkansas," Weed Technology, vol. 22, no. 1, pp. 108-113, 2008. 
[33] L. E. Steckel, C. L. Main, A. T. Ellis, and T. C. Mueller, "Palmer amaranth (Amaranthus palmeri) in Tennessee has low level glyphosate resistance," Weed Technology, vol. 22, no. 1, pp. 119-123, 2008.

[34] J. S. Holt, "Ecological fitness of herbicide-resistant weeds," Proceedings of Second International Weed Control Congress, pp. 387-392, 1996.

[35] M. A. Jasieniuk, A. L. Brûlè-Babel, and I. N. Morrison, "The evolution and genetics of herbicide resistance in weeds," Weed Science, vol. 44, no. 1, pp. 176-193, 1996.

[36] N. Jordan, "Effects of the triazine-resistance mutation on fitness in Amaranthus hybridus (smooth pigweed)," Journal of Applied Ecology, vol. 33, no. 1, pp. 141-150, 1996.

[37] N. Jordan, "Fitness effects of the triazine resistance mutation in Amaranthus hybridus: relative fitness in maize and soyabean crops," Weed Research, vol. 39, no. 6, pp. 493-505, 1999.

[38] F. J. Tardif, I. Rajcan, and M. Costea, "A mutation in the herbicide target site acetohydroxyacid synthase produces morphological and structural alterations and reduces fitness in Amaranthus powellii," New Phytologist, vol. 169, no. 2, pp. 251-264, 2006.

[39] Y. Menchari, B. Chauvel, H. Darmency, and C. Délye, "Fitness costs associated with three mutant acetyl-coenzyme A carboxylase alleles endowing herbicide resistance in black-grass Alopecurus myosuroides," Journal of Applied Ecology, vol. 45, no. 3, pp. 939-947, 2008.

[40] C. Preston and A. M. Wakelin, "Resistance to glyphosate from altered herbicide translocation patterns," Pest Management Science, vol. 64, no. 4, pp. 372-376, 2008.

[41] A. M. Wakelin and C. Preston, "The cost of glyphosate resistance: is there a fitness penalty associated with glyphosate resistance in annual ryegrass?" in Proceedings of 15th Australian Weeds Conference, pp. 515-518, 2006.

[42] R. S. Baucom and R. Mauricio, "Fitness costs and benefits of novel herbicide tolerance in a noxious weed," Proceedings of the National Academy of Sciences of the United States of America, vol. 101, no. 36, pp. 13386-13390, 2004.

[43] S. I. Warwick, "Herbicide resistance in weedy plants: physiology and population biology," Annual Review of Ecology and Systematics, vol. 22, no. 1, pp. 95-114, 1991.

[44] M. M. Vila-Aiub, P. Neve, and S. B. Powles, "Fitness costs associated with evolved herbicide resistance alleles in plants," New Phytologist, vol. 184, no. 4, pp. 751-767, 2009.

[45] B. P. Pedersen, P. Neve, C. Andreasen, and S. B. Powles, "Ecological fitness of a glyphosate-resistant Lolium rigidum population: growth and seed production along a competition gradient," Basic and Applied Ecology, vol. 8, no. 3, pp. 258-268, 2007.

[46] O. A. Chivinge and M. A. Schweppenhauser, "Competition of soybean with blackjack (Bidens pilosa L.) and pigweed (Amaranthus hybridus L.)," African Crop Science Journal, vol. 3, no. 1, pp. 73-82, 1995.

[47] N. R. Burgos, Y. I. Kuk, and R. E. Talbert, “Amaranthus palmeri resistance and differential tolerance of Amaranthus palmeri and Amaranthus hybridus to ALS-inhibitor herbicides," Pest Management Science, vol. 57, no. 5, pp. 449-457, 2001.

[48] B. J. Gossett and J. E. Toler, "Differential control of Palmer amaranth (Amaranthus palmeri) and smooth pigweed (Amaranthus hybridus) by postemergence herbicides in soybean (Glycine max)," Weed Technology, vol. 13, no. 1, pp. 165-168, 1999.

[49] M. J. Horak and D. E. Peterson, "Biotypes of palmar amaranth (Amaranthus palmeri) and common waterhemp (Amaranthus rudis) are resistant to imazethapyr and thifensulfuron," Weed Technology, vol. 9, no. 1, pp. 192-195, 1995.

[50] J. A. Bond and L. R. Oliver, "Comparative growth of Palmer amaranth (Amaranthus palmeri) accessions," Weed Science, vol. 54, no. 1, pp. 121-126, 2006.

[51] A. Chandi, Characterization and management of selected herbicide resistant weed populations [Ph.D. dissertation], North Carolina State University, Raleigh, NC, USA, 2011. 


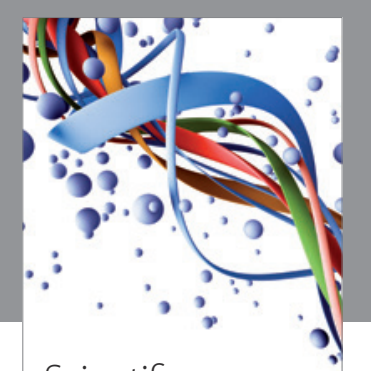

Scientifica
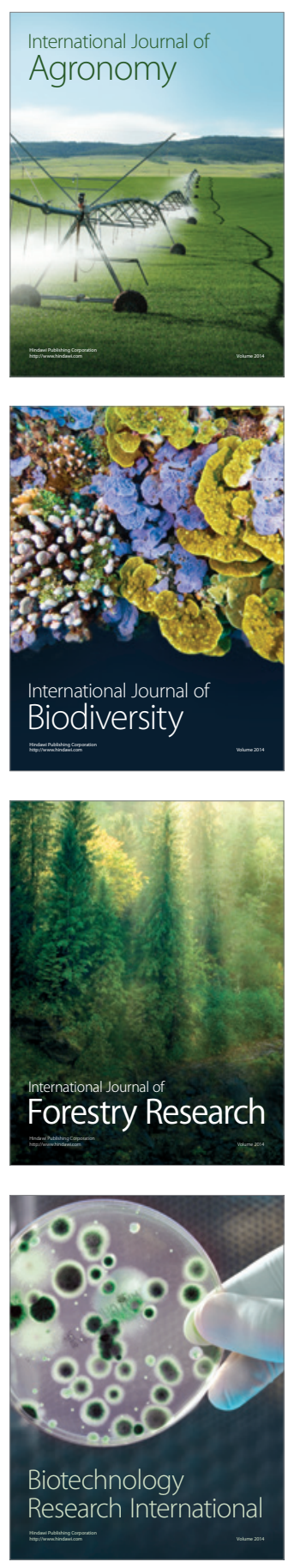
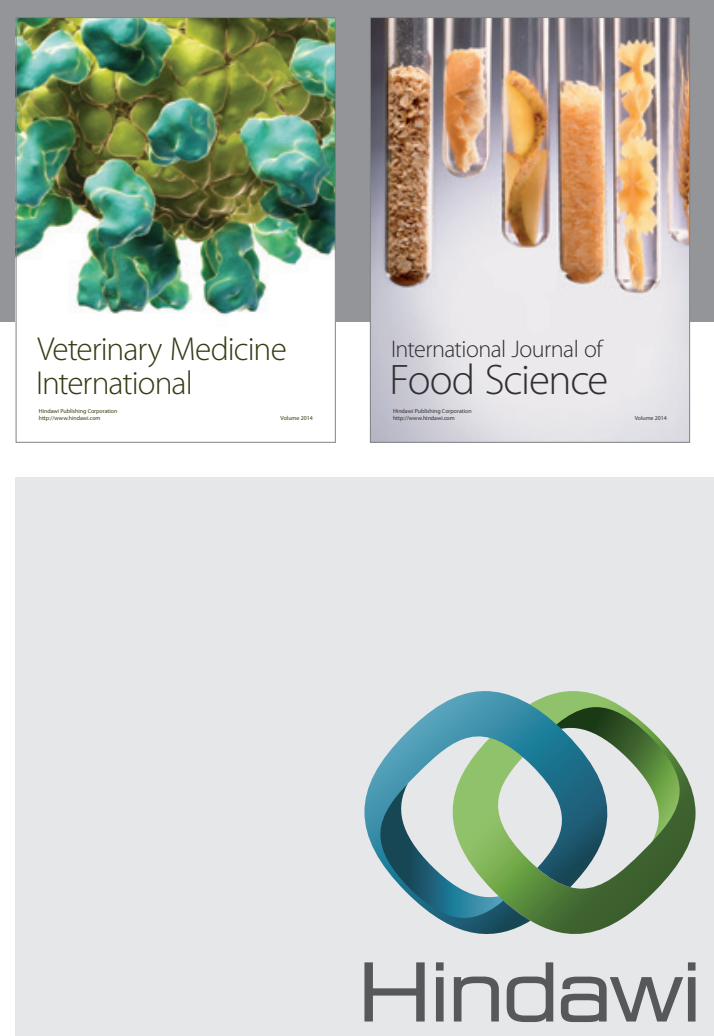

Submit your manuscripts at

http://www.hindawi.com
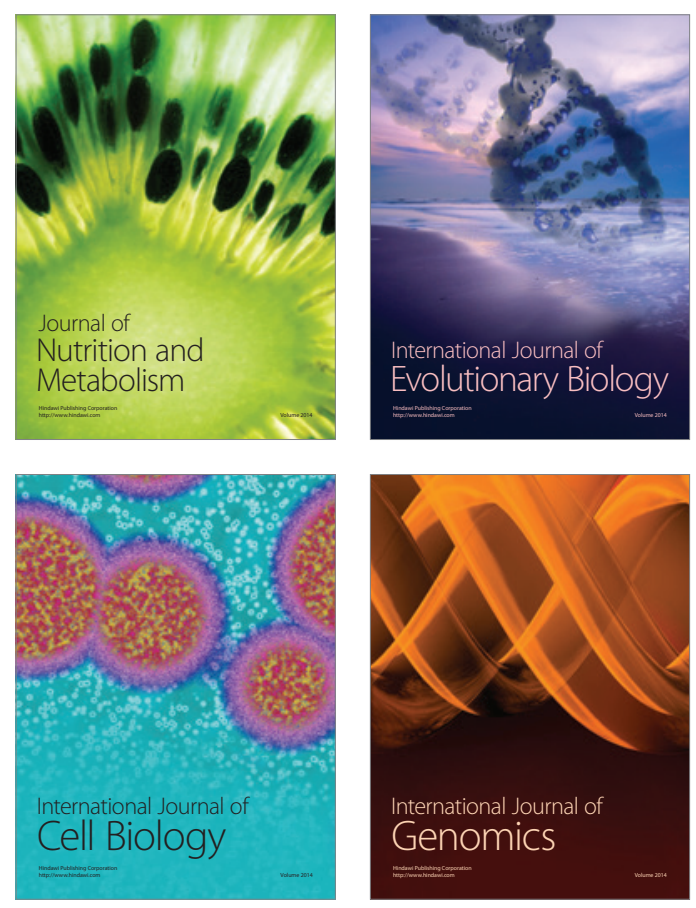
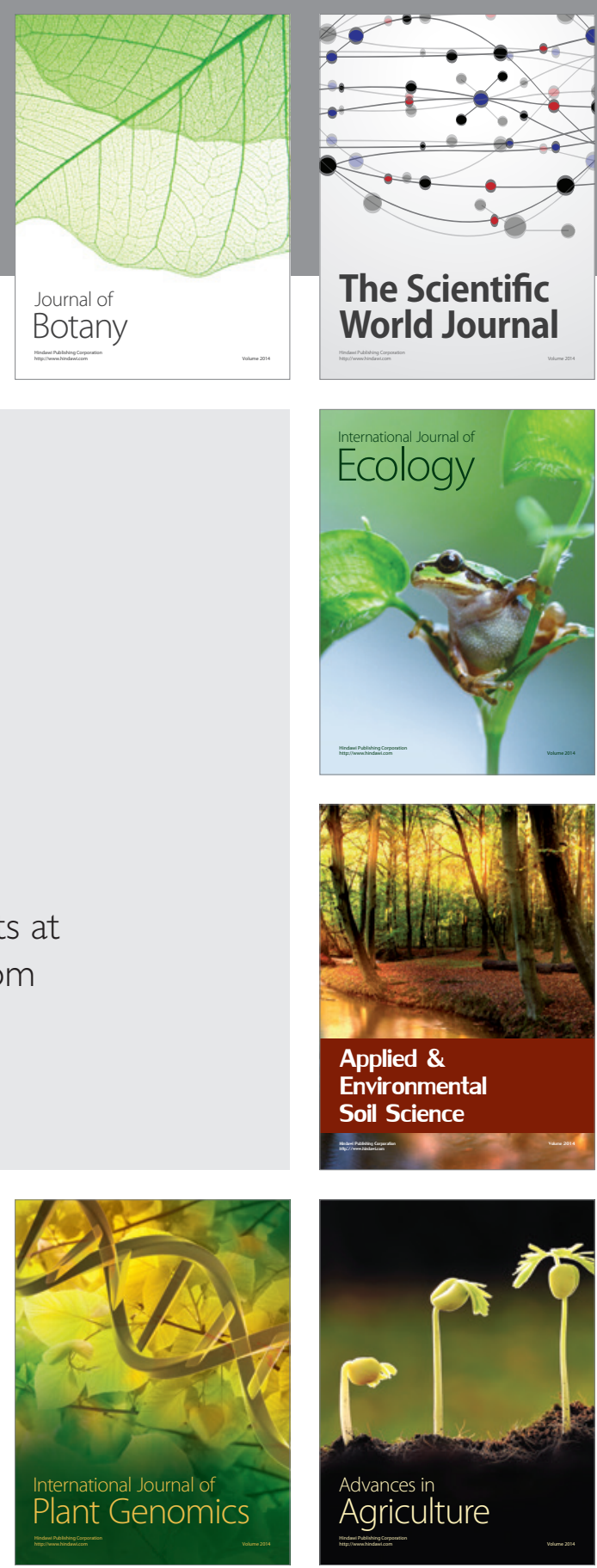

The Scientific World Journal
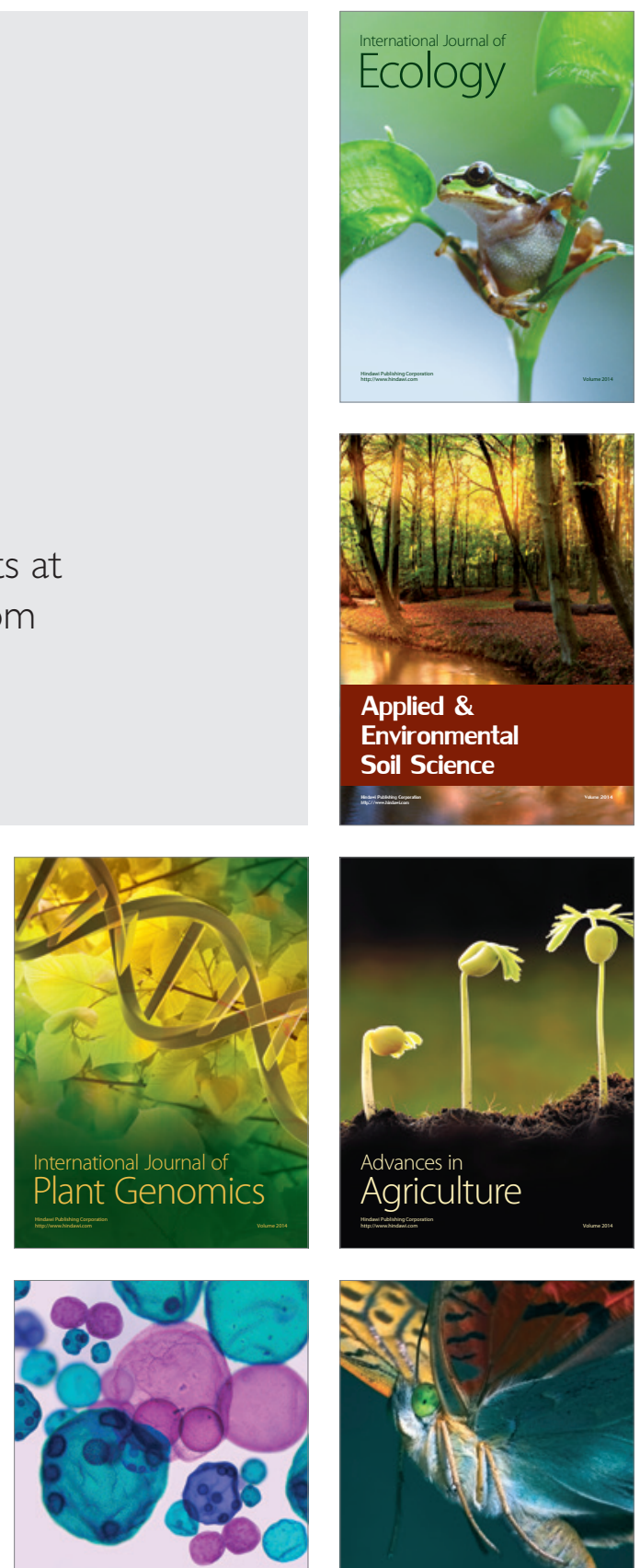

International Journal of Microbiology

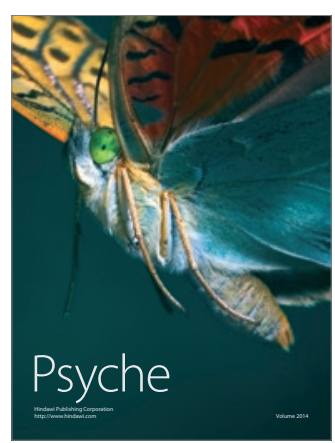

